\title{
Predictors of postoperative complication and prolonged intensive care unit stay after complete pericardiectomy in tuberculous constrictive pericarditis
}

Likui Fang ${ }^{1 *}$, Guocan Yu', Jinpeng Huang ${ }^{2}$, Wuchen Zhao ${ }^{1}$ and Bo Ye ${ }^{1}$

\begin{abstract}
Background: The risk factors of postoperative outcomes after pericardiectomy in tuberculous constrictive pericarditis have still been unclear. This study aimed to investigate the predictors of postoperative complication and prolonged intensive care unit (ICU) stay in the patients with tuberculous constrictive pericarditis undergoing pericardiectomy.

Methods: A total of 88 patients with tuberculous constrictive pericarditis undergoing pericardiectomy were retrospectively enrolled. Logistic regression and Cox regression analysis were performed to identify the predictors of postoperative complication and prolonged ICU stay, respectively.

Results: All patients underwent complete pericardiectomy and 35 (39.8\%) had postoperative complication with no mortality within 30 days after surgery and no in-hospital deaths. Postoperative complication prolonged postoperative ICU stay $(P<0.001)$, duration of chest drainage $(P<0.001)$ and postoperative hospital stay $(P<0.001)$. Preoperative NYHA functional class $(P=0.004, \mathrm{OR} 4.051,95 \% \mathrm{Cl} 1.558-10.533)$ and preoperative central venous pressure (CVP) $(P=0.031, \mathrm{OR} 1.151,95 \% \mathrm{Cl} 1.013-1.309)$ were independent risk factors of postoperative complication. Postoperative complication ( $P<0.001, \mathrm{HR} 4.132,95 \% \mathrm{Cl}$ 2.217-7.692) was the independent risk factor for prolonged ICU stay.

Conclusion: Complete pericardiectomy was associated with high risk of postoperative complication in tuberculous constrictive pericarditis. Poor preoperative NYHA functional class and high preoperative CVP were shown to predict postoperative complication which was the predictor of prolonged ICU stay.
\end{abstract}

Keywords: Tuberculous constrictive pericarditis, Complete pericardiectomy, Postoperative complication, Intensive care unit stay

\footnotetext{
* Correspondence: 21618100@zju.edu.cn

'Department of Thoracic Surgery, Hangzhou Red Cross Hospital, Hangzhou 310003, China

Full list of author information is available at the end of the article
}

(c) The Author(s). 2020 Open Access This article is licensed under a Creative Commons Attribution 4.0 International License, which permits use, sharing, adaptation, distribution and reproduction in any medium or format, as long as you give appropriate credit to the original author(s) and the source, provide a link to the Creative Commons licence, and indicate if changes were made. The images or other third party material in this article are included in the article's Creative Commons licence, unless indicated otherwise in a credit line to the material. If material is not included in the article's Creative Commons licence and your intended use is not permitted by statutory regulation or exceeds the permitted use, you will need to obtain permission directly from the copyright holder. To view a copy of this licence, visit http://creativecommons.org/licenses/by/4.0/. The Creative Commons Public Domain Dedication waiver (http://creativecommons.org/publicdomain/zero/1.0/) applies to the data made available in this article, unless otherwise stated in a credit line to the data. 


\section{Introduction}

Tuberculosis is one of the globally significant infectious diseases with a high incidence and is the leading cause of infection related deaths, especially in developing countries [1]. In the low and middle income areas, tuberculosis is the most common cause of constrictive pericarditis with the reported incidence ranging from 23 to $91 \%[2,3]$. Surgical intervention has been recommended if there has been persistent clinical evidence of pericardial constriction after anti-tuberculous therapy [4]. Pericardiectomy is the standard surgical method for constrictive pericarditis [5]. In spite of its satisfactory effect in relieving pericardial constriction, pericardiectomy is accompanied by high risk of postoperative complication and in-hospital mortality [6-8].

In current clinical practice, the extent of pericardiectomy is varied according to surgeons' experience and surgical difficulty. However, complete pericardiectomy has been reported to be superior to partial pericardiectomy in the improvement of hemodynamics and prognosis [9, 10], while the factors influencing the outcomes after pericardiectomy still remain unclear, especially in tuberculous constrictive pericarditis. This study aimed to identify the determinants of postoperative complication and prolonged intensive care unit (ICU) stay after pericardiectomy in tuberculous constrictive pericarditis.

\section{Methods}

\section{Patients selection}

There were one hundred and eight patients who were diagnosed as tuberculous constrictive pericarditis in our department from August 2012 to August 2019. We retrospectively reviewed their records and included the patients undergoing pericardiectomy in this study. The diagnosis of tuberculous pericarditis was based on bacteriological detection, nucleic acid detection and pathological examination. The diagnosis of constrictive pericarditis was determined mainly from clinical symptoms, imaging examinations and central venous pressure (CVP). Finally, a total of 88 patients were enrolled and their clinical characteristics were collected from the hospital electronic medical records system. The study protocol was approved by the Institutional Review Board of Hangzhou Red Cross Hospital.

\section{Perioperative process}

Preoperative preparations included routine blood test, cardiopulmonary function assessment and imaging examination. The evaluation of pericardium mainly depended on cardiac ultrasound and contrast-enhanced computed tomography. Percutaneous internal jugular vein puncture and catheterization were performed preoperatively to measure the CVP.
All patients underwent general anesthesia and were placed in horizontal position. Median sternotomy was routinely performed in all cases without the use but with the preparation of cardiopulmonary bypass. The extent of complete pericardiectomy was defined as the resection of anterolateral pericardium between the two phrenic nerves including the pericardium lying on the ventricles, the basal pericardium over the diaphragmatic surface, the pericardium on the great arteries and the pericardium from superior vena cava-right atrium junction to inferior vena cava-right atrium junction $[7,11]$. Other less extent was regarded as partial pericardiectomy. All patients were routinely admitted to ICU after surgery and transferred to the normal ward when the condition was steady. Postoperative complications were defined as the comorbidities that occurred after surgery but did not exist before.

\section{Statistical analysis}

The enrolled patients were assigned to the postoperative complication group and the no postoperative complication group. The measurement data and numeration data of two groups were statistically analyzed with t test and $\chi^{2}$ test respectively. If the $P$ value of any clinical characteristics was $<0.1$, multivariate analysis was performed for those characteristics by the binary logistic regression to identify the factors predicting postoperative complication. Univariate and multivariate Cox regression analysis were performed to identify the independent risk factors of prolonged ICU stay. The length of ICU stay was compared between the two groups by the Kaplan-Meier curves and the log-rank test to further analyzed the association between the length of ICU stay and postoperative complication. All the above analysis was conducted by SPSS software (version 24.0, IBM SPSS Inc. United States). Statistical significance was set at $P$ value $<0.05$ (All $P$ values presented were 2 -sided).

\section{Results}

Postoperative complication and outcomes

We identified 88 patients with tuberculous constrictive pericarditis over the 7-year time period and all of them underwent complete pericardiectomy without the use of cardiopulmonary bypass. A total of 35 patients (39.8\%) suffered postoperative complication (Table 1). Among these patients, the majority of cases $(N=23,65.7 \%)$ had hypoalbuminemia. Low cardiac output occurred in 11 patients $(31.4 \%)$, followed by pulmonary infection $(N=7$, $20.0 \%$ ). Arrhythmia occurred in 3 patients $(8.6 \%)$ and wound infection in $2(5.7 \%)$. Liver dysfunction was detected in 2 patients $(5.7 \%)$ as well as hypokalemia $(N=2$, 5.7\%). Pulmonary embolism occurred in 1 patient (2.9\%). It should be noted that 16 patients (45.7\%) had two or more postoperative complications. 
Table 1 Postoperative complication after pericardiectomy in study patients

\begin{tabular}{ll}
\hline Complication & $N=35$ \\
\hline Hypoalbuminemia $^{\text {a }}$ & $23(65.7 \%)$ \\
Low cardiac output $^{\text {b }}$ & $11(31.4 \%)$ \\
Pneumonia & $7(20.0 \%)$ \\
Atrial fibrillation $_{\text {Wound infection }}$ & $3(8.6 \%)$ \\
Liver dysfunction $^{c}$ & $2(5.7 \%)$ \\
Hypokalemia $_{\text {Pulmonary embolism }}$ & $2(5.7 \%)$ \\
\hline
\end{tabular}

Values presented as $\mathrm{N}$ (percentage)

There were 16 patients suffering two or more postoperative complications

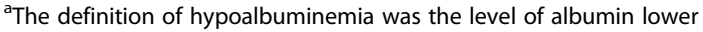
than $30 \mathrm{~g} / \mathrm{L}$

${ }^{b}$ The definition of low cardiac output included cardiac index less than $2.0 \mathrm{~L} /$ $\mathrm{min} / \mathrm{m} 2$ and systolic blood pressure less than $90 \mathrm{mmHg}$, in conjunction with signs of tissue hypoperfusion in the absence of hypovolemia

'The definition of liver dysfunction included alanine aminotransferase $>50 \mathrm{U} / \mathrm{L}$, aspartate aminotransferase $>40 \mathrm{U} / \mathrm{L}$ or rising of bilirubin in the blood

The short term outcomes of postoperative complication were showed in Table 2. The patients with postoperative complication had longer postoperative ICU stay $(P<0.001)$ and postoperative hospital stay $(P<0.001)$ than those without postoperative complication. The duration of chest drainage was also prolonged in the postoperative complication group $(P<0.001)$, while postoperative NYHA functional class of patients with postoperative complication was similar to that of those without postoperative complication $(P=0.085)$. It was notable that there was no mortality within 30 days after surgery and no in-hospital death.

\section{Risk factors of postoperative complication}

A total of $35(39.8 \%)$ and $53(60.2 \%)$ patients were assigned to the postoperative complication group and the no postoperative complication group, respectively. The association between postoperative complication and perioperative characteristics were shown in Table 3. Statistical differences were observed in symptom duration $(P=0.014)$, preoperative NYHA functional class $(P=0.019)$, pulse rate $(P=0.009)$, preoperative CVP $(P=0.041)$, pleural effusion $(P=0.035)$ and serum sodium $(P=0.038)$.

Multivariate logistic analysis was further performed for the characteristics whose $P$ values were $<0.1$ to identify the risk factors of postoperative complication. As shown in Table 3, symptom duration, pulse rate, pleural effusion, pericardial thickness, albumin and serum sodium were not statistically associated with postoperative complication. The results revealed that preoperative NYHA functional class $(P=0.004$, OR $4.051,95 \%$ CI $1.558-$ 10.533) and preoperative CVP $(P=0.031$, OR 1.151 , 95\%CI 1.013-1.309) were independent risk factors of postoperative complication.

\section{Factors associated with length of ICU stay}

The relationships between the perioperative factors and the length of ICU stay were analyzed with Cox regression model. Univariate Cox regression analysis showed that the length of ICU stay was significantly associated with age $(P=0.040)$, preoperative NYHA functional class $(P=0.042)$ and postoperative complications $(P<0.001)$. Additional multivariate Cox regression analysis proved that postoperative complication was the independent risk factor for prolonged ICU stay $(P<0.001$, HR 4.132, 95\%CI 2.217-7.692; Table 4). The ICU stay of two groups was compared by Kaplan-Meier curves (Fig. 1). The log-rank test showed that the patients with postoperative complication had longer ICU stay than those without postoperative complication $(P<0.001)$.

\section{Discussion}

Constrictive pericarditis is an uncommon but potentially life-threatening disease. Because of the inflammatory disorder and fibrosis, pericardium becomes inelastic and

Table $\mathbf{2}$ Outcomes of study patients stratified by postoperative complication status

\begin{tabular}{|c|c|c|c|}
\hline \multirow[t]{2}{*}{ Variables } & \multicolumn{2}{|c|}{ Postoperative complication } & \multirow[t]{2}{*}{$P$ value } \\
\hline & Yes $(N=35)$ & No $(N=53)$ & \\
\hline Postoperative ICU stay, days & $4.8 \pm 2.4$ & $2.1 \pm 1.1$ & $<0.001$ \\
\hline Duration of chest drainage, days & $17.3 \pm 8.3$ & $9.2 \pm 2.9$ & $<0.001$ \\
\hline Postoperative hospital stay, days & $24.0 \pm 10.1$ & $14.1 \pm 3.4$ & $<0.001$ \\
\hline Postoperative NYHA functional class & & & 0.085 \\
\hline । & $20(57.1 \%)$ & $42(79.2 \%)$ & \\
\hline$\|$ & $14(40.0 \%)$ & $10(18.9 \%)$ & \\
\hline III & $1(2.9 \%)$ & $1(1.9 \%)$ & \\
\hline Mortality within 30 days & $0(0.0 \%)$ & $0(0.0 \%)$ & / \\
\hline In-hospital deaths & $0(0.0 \%)$ & $0(0.0 \%)$ & / \\
\hline
\end{tabular}

Values presented as mean \pm standard deviation for continuous variables and $\mathrm{N}$ (percentage) for categorical variables ICU intensive care unit, NYHA New York Heart Association 
Table 3 The analysis of perioperative characteristics predicting postoperative complication

\begin{tabular}{|c|c|c|c|c|c|c|}
\hline \multirow[t]{2}{*}{ Variables } & \multicolumn{2}{|c|}{ Postoperative complication } & \multirow{2}{*}{$\begin{array}{l}P \\
\text { value }\end{array}$} & \multicolumn{3}{|c|}{ Multivariate analysis } \\
\hline & Yes $(N=35)$ & No $(N=53)$ & & $\mathrm{OR}$ & $95 \% \mathrm{Cl}$ & $P$ value \\
\hline Sex & & & 0.310 & & & \\
\hline Male & $29(82.9 \%)$ & $39(73.6 \%)$ & & & & \\
\hline Female & $6(17.1 \%)$ & $14(26.4 \%)$ & & & & \\
\hline Age, years & $56.6 \pm 18.4$ & $52.7 \pm 15.2$ & 0.288 & & & \\
\hline Symptom duration, months & $2.1 \pm 2.1$ & $3.8 \pm 4.1$ & 0.014 & 1.160 & $0.909-1.480$ & 0.233 \\
\hline Preoperative NYHA functional class & & & 0.019 & 4.051 & $1.558-10.533$ & 0.004 \\
\hline । & $0(0.0 \%)$ & $7(13.2 \%)$ & & & & \\
\hline$\|$ & $9(25.7 \%)$ & $20(37.7 \%)$ & & & & \\
\hline III & $22(62.9 \%)$ & $25(47.2 \%)$ & & & & \\
\hline IV & $4(11.4 \%)$ & $1(1.9 \%)$ & & & & \\
\hline Hypertension & $5(14.3 \%)$ & $9(17.0 \%)$ & 0.735 & & & \\
\hline Diabetes & $2(5.7 \%)$ & $3(5.7 \%)$ & 0.991 & & & \\
\hline Arrhythmia & $8(22.9 \%)$ & $6(11.3 \%)$ & 0.148 & & & \\
\hline $\mathrm{BMl}, \mathrm{kg} / \mathrm{m} 2$ & $21.0 \pm 2.9$ & $21.8 \pm 3.6$ & 0.263 & & & \\
\hline $\mathrm{SBP}, \mathrm{mmHg}$ & $113.8 \pm 14.0$ & $116.7 \pm 16.0$ & 0.386 & & & \\
\hline $\mathrm{DBP}, \mathrm{mmHg}$ & $79.3 \pm 12.0$ & $79.1 \pm 12.3$ & 0.914 & & & \\
\hline Pulse rate (beats/min) & $108.0 \pm 15.5$ & $99.0 \pm 15.4$ & 0.009 & 1.026 & $0.982-1.073$ & 0.253 \\
\hline Preoperative $\mathrm{CVP}, \mathrm{CmH}_{2} \mathrm{O}$ & $27.9 \pm 5.8$ & $25.2 \pm 5.3$ & 0.041 & 1.151 & $1.013-1.309$ & 0.031 \\
\hline Pleural effusion & & & 0.035 & 6.057 & $0.675-54.367$ & 0.108 \\
\hline $\begin{array}{l}\text { Unilateral } \\
\text { Bilateral }\end{array}$ & $\begin{array}{l}2(5.7 \%) \\
33(94.3 \%)\end{array}$ & $\begin{array}{l}8(15.1 \%) \\
39(73.6 \%)\end{array}$ & & & & \\
\hline Ascites & $20(57.1 \%)$ & $27(50.9 \%)$ & 0.568 & & & \\
\hline Pericardial effusion & $27(77.1 \%)$ & $41(77.4 \%)$ & 0.981 & & & \\
\hline Pericardial calcification & $10(28.6 \%)$ & $12(22.6 \%)$ & 0.530 & & & \\
\hline Pericardial thickness, mm & $11.2 \pm 2.9$ & $9.8 \pm 3.4$ & 0.055 & 1.126 & $0.902-1.406$ & 0.293 \\
\hline LVEF, \% & $58.5 \pm 6.9$ & $58.9 \pm 7.1$ & 0.759 & & & \\
\hline Hepatomegaly & $1(2.9 \%)$ & $1(1.9 \%)$ & 0.767 & & & \\
\hline Hemoglobin, g/dl & $124.9 \pm 15.0$ & $121.1 \pm 14.8$ & 0.248 & & & \\
\hline $\mathrm{CRP}, \mathrm{mg} / \mathrm{L}$ & $23.9 \pm 20.1$ & $23.6 \pm 30.8$ & 0.956 & & & \\
\hline $\mathrm{ESR}, \mathrm{mm} / \mathrm{h}$ & $27.7 \pm 18.3$ & $27.8 \pm 27.9$ & 0.995 & & & \\
\hline Albumin, $g / L$ & $31.6 \pm 4.1$ & $33.3 \pm 5.1$ & 0.087 & 1.011 & $0.852-1.201$ & 0.898 \\
\hline Serum sodium, mmol/L & $136.7 \pm 3.1$ & $138.2 \pm 3.5$ & 0.038 & 1.098 & $0.887-1.360$ & 0.390 \\
\hline Serum potassium, $\mathrm{mmol} / \mathrm{L}$ & $4.0 \pm 0.5$ & $3.9 \pm 0.5$ & 0.466 & & & \\
\hline Serum creatinine, $\mu \mathrm{mol} / \mathrm{L}$ & $84.4 \pm 16.8$ & $79.8 \pm 12.4$ & 0.144 & & & \\
\hline Operative duration, min & $249.5 \pm 45.6$ & $233.3 \pm 64.9$ & 0.202 & & & \\
\hline Blood loss, ml & $199.7 \pm 163.9$ & $166.0 \pm 86.5$ & 0.212 & & & \\
\hline Intraoperative fluid infusion, ml & $1842.9 \pm 446.9$ & $1779.3 \pm 526.6$ & 0.558 & & & \\
\hline Postoperative $\mathrm{CVP}, \mathrm{cmH}_{2} \mathrm{O}$ & $15.0 \pm 6.6$ & $13.6 \pm 5.2$ & 0.315 & & & \\
\hline
\end{tabular}

Values presented as $\mathrm{N}$ (percentage) for categorical variables and mean \pm standard deviation for continuous variables

$O R$ odds ratio, $C I$ confidence interval, NYHA New York Heart Association, BMI body mass index, SBP systolic blood pressure, DBP diastolic blood pressure, CVP central venous pressure, LVEF left ventricular ejection fraction (measured on echocardiogram), CRP C-reactive protein, ESR erythrocyte sedimentation rate

then inhibits the cardiac filling. This process leads to the diastolic heart failure in the end with unfavorable clinical outcome [12]. Early surgical intervention was reported to play a positive role in reducing mortality rate [13, 14], but the diagnosis seems to be challenging in the early stage. The detection of constrictive pericarditis often 
Table 4 Cox regression analysis of factors associated with the length of ICU stay

\begin{tabular}{|c|c|c|c|c|c|c|}
\hline \multirow[t]{2}{*}{ Variables } & \multicolumn{3}{|c|}{ Univariate analysis } & \multicolumn{3}{|c|}{ Multivariate analysis } \\
\hline & $P$ value & $\mathrm{HR}$ & $95 \% \mathrm{Cl}$ & $P$ value & $\mathrm{HR}$ & $95 \% \mathrm{Cl}$ \\
\hline Sex & 0.639 & 1.139 & $0.662-1.957$ & & & \\
\hline Age & 0.040 & 1.014 & $1.001-1.027$ & 0.559 & 1.004 & $0.990-1.019$ \\
\hline Symptom duration & 0.333 & 1.031 & $0.969-1.096$ & & & \\
\hline Preoperative NYHA functional class & 0.042 & 1.408 & $1.013-1.957$ & 0.470 & 1.134 & $0.806-1.595$ \\
\hline Hypertension & 0.242 & 1.449 & $0.778-2.703$ & & & \\
\hline Diabetes & 0.481 & 1.387 & $0.558-3.448$ & & & \\
\hline Arrhythmia & 0.533 & 1.209 & $0.665-2.199$ & & & \\
\hline Body weight & 0.800 & 1.003 & $0.983-1.022$ & & & \\
\hline SBP & 0.424 & 1.007 & $0.990-1.024$ & & & \\
\hline $\mathrm{DBP}$ & 0.364 & 1.009 & $0.989-1.030$ & & & \\
\hline Pulse rate & 0.742 & 1.003 & $0.987-1.018$ & & & \\
\hline Preoperative CVP & 0.509 & 1.016 & $0.969-1.065$ & & & \\
\hline Pleural effusion & 0.255 & 1.285 & $0.834-1.980$ & & & \\
\hline Ascites & 0.164 & 1.380 & $0.877-2.171$ & & & \\
\hline Pericardial effusion & 0.953 & 1.016 & $0.599-1.724$ & & & \\
\hline Pericardial calcification & 0.897 & 1.034 & $0.620-1.727$ & & & \\
\hline Pericardial thickness & 0.807 & 1.009 & $0.938-1.085$ & & & \\
\hline LVEF & 0.534 & 1.012 & $0.975-1.051$ & & & \\
\hline Hepatomegaly & 0.482 & 2.043 & $0.280-14.927$ & & & \\
\hline Hemoglobin & 0.657 & 1.004 & $0.987-1.020$ & & & \\
\hline CRP & 0.481 & 1.005 & $0.992-1.017$ & & & \\
\hline ESR & 0.979 & 1.000 & $0.989-1.011$ & & & \\
\hline Albumin & 0.537 & 1.016 & $0.966-1.068$ & & & \\
\hline Serum sodium & 0.473 & 1.025 & $0.957-1.098$ & & & \\
\hline Serum potassium & 0.410 & 1.223 & $0.757-1.977$ & & & \\
\hline Serum creatinine & 0.542 & 1.005 & $0.989-1.021$ & & & \\
\hline Operative duration & 0.519 & 1.001 & $0.997-1.006$ & & & \\
\hline Blood loss & 0.145 & 1.001 & $1.000-1.003$ & & & \\
\hline Intraoperative fluid infusion & 0.642 & 1.000 & $1.000-1.001$ & & & \\
\hline Postoperative CVP & 0.480 & 1.016 & $0.972-1.063$ & & & \\
\hline Postoperative complication & $<0.001$ & 4.505 & $2.494-8.130$ & $<0.001$ & 4.132 & $2.217-7.692$ \\
\hline
\end{tabular}

HR hazard ratio, Cl confidence interval, NYHA New York Heart Association, SBP systolic blood pressure, DBP diastolic blood pressure, CVP central venous pressure, LVEF left ventricular ejection fraction (measured on echocardiogram), CRP C-reactive protein, ESR erythrocyte sedimentation rate

relies on the typical clinical symptoms such as dyspnea and clinical signs such as jugular vein distention. Imaging examinations such as chest $\mathrm{CT}$ and cardiac MRI are important in the identification of pericardial effusion, calcification and thickening [12, 14, 15]. Meticulous echocardiographic examination is also valuable in the assessment of pericardial condition. Invasive haemodynamic catheterization and pressure measurement were of great significance in the diagnostic confirmation and the evaluation of the constrictive extent [16].

The definitive treatment for constrictive pericarditis is surgical pericardiectomy [17]. The surgical methods are classified as complete pericardiectomy and partial pericardiectomy according to the extent of pericardial resection. Complete pericardiectomy has been proven to be not only associated with lower perioperative mortality [9] but also confer significant long-term survival benefit and clinical functional improvement $[10,18]$. Generally, pericardiectomy can be performed through either median sternotomy or left anterolateral thoracotomy, while median sternotomy provides adequate exposure of the right atrium, right ventricle and the vena cava, thus enabling extensive pericardial resection [19]. 


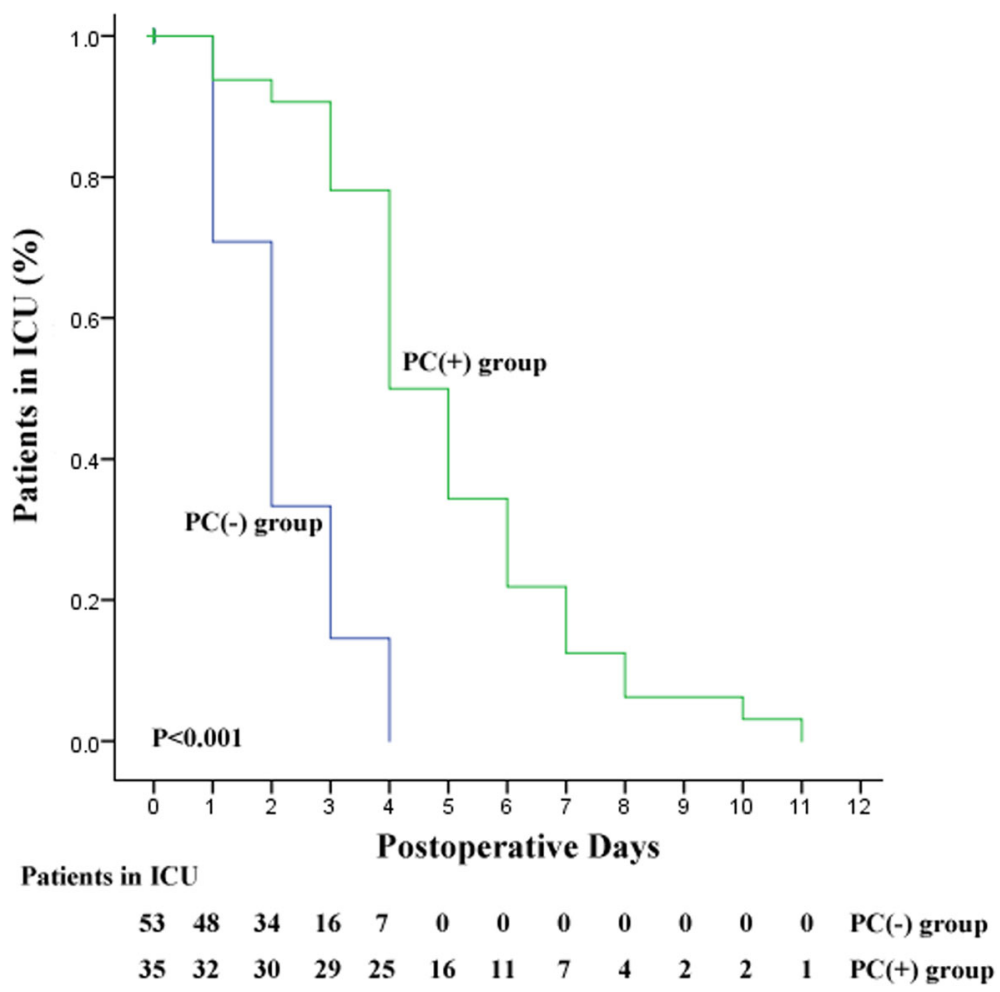

Fig. 1 Kaplan-Meier curves comparing the length of ICU stay after surgery for the patients with and without postoperative complications. PC(+) group, the postoperative complication group; $\mathrm{PC}(-)$ group, the no postoperative complication group

Despite the undoubtable effectiveness in treating constrictive pericarditis, pericardiectomy is associated with high risk of postoperative complication and mortality. A nationwide study in US revealed that the in-hospital complication and mortality rates after pericardiectomy were approximately 48 and $8 \%$, respectively [8]. Also, Tokuda, Y. and his colleagues conducted a nationwide study on the outcome of pericardiectomy for constrictive pericarditis in Japan which showed the operative mortality was $10 \%$ and the major morbidity such as bleeding requiring reoperation was $15 \%$ [6]. In addition, Busch, C. et al. reviewed 97 consecutive patients undergoing surgery for constrictive pericarditis and reported that 1-year and 5-year survival rates were 66.5 and $51.6 \%$, respectively [20]. Another retrospective study including 98 cases showed 1-year, 5-year, and 10-year survival rates were 82.5, 64.3, and 49.2\%, respectively [21]. Although there are many researches about the surgical treatment for constrictive pericarditis in developed countries, the studies on tuberculous constrictive pericarditis have been limited in recent years due to the decreased incidence of tuberculosis worldwide. However, tuberculosis still remains the major etiology of constrictive pericarditis in developing countries $[2,3]$.

We have analyzed the short-term outcome of the patients with tuberculous constrictive pericarditis undergoing complete pericardiectomy over 7 years in our department. Although nearly $40 \%$ of patients in our study suffering postoperative complication, there was no mortality within 30 days after surgery and no in-hospital death. Hypoalbuminemia was the major postoperative complication possibly because of the negative nitrogen balance after surgery. The incidence of low cardiac output was also high enough to warrant attention, because it was proven to be the major contributor to in-hospital death in other studies [3, 22, 23]. In our study, postoperative complication was seemed to be associated with symptom duration, preoperative NYHA functional class, pulse rate, preoperative CVP, pleural effusion and serum sodium, while multivariate analysis eventually proved that poor preoperative NYHA functional class and high preoperative CVP were independent risk factors of postoperative complication, which might provide a valuable guidance for preoperative preparation and risk evaluation. We also found that postoperative complication significantly prolonged the postoperative ICU stay, duration of chest drainage and postoperative hospital stay. Additionally, postoperative complication was the independent risk factor for prolonged ICU stay. It should be emphasized that all patients undergoing complete pericardiectomy in our department were not routinely performed cardiopulmonary bypass, which was also proven to be safe in other studies [24, 25]. 
There are several limitations in this study. First, this is a single-center retrospective research that inevitably has the selection bias. Secondly, some important data such as duration of anti-tuberculosis medication, rate of prolonged intubation and duration of inotropic medication are unavailable due to the retrospective design. Finally, survival outcomes only include the mortality within 30 days after surgery and in-hospital deaths. Long-term outcome is required to be analyzed in the future.

\section{Conclusions}

This study showed that complete pericardiectomy was associated with high risk of postoperative complication despite its benefits. Poor preoperative NYHA functional class and high preoperative CVP were shown to predict postoperative complication which was the predictor of prolonged ICU stay. This study has confirmed the need for early surgical intervention before the symptoms deteriorate to poor NYHA class or diastolic heart failure.

\section{Abbreviations \\ CVP: Central venous pressure; ICU: Intensive care unit; CT: Computed tomography; MRI: Magnetic resonance imaging; NYHA: New York Heart Association; BMI: Body mass index; OR: Odds ratio; Cl: Confidence interval; SBP: Systolic blood pressure; DBP: Diastolic blood pressure; LVEF: Left ventricular ejection fraction; CRP: C-reactive protein; ESR: Erythrocyte sedimentation rate; HR: Hazard ratio}

\section{Acknowledgements}

Not applicable.

\section{Authors' contributions}

Drs. Likui Fang and Bo Ye contributed to the conception and design of the work. Drs. Likui Fang and Wuchen Zhao contributed to data analysis and editing the manuscript. Drs. Likui Fang, Guocan Yu and Jinpeng Huang contributed to data acquisition, statistical analysis and interpretation of the data. Drs. Guocan Yu and Bo Ye contributed to the revision of the manuscript. All authors have approved the final draft of the manuscript.

\section{Funding}

No funding.

\section{Availability of data and materials}

The datasets used and/or analyzed during the current study are available from the corresponding author on reasonable request.

\section{Ethics approval and consent to participate}

The study protocol was approved by the Institutional Review Board of Hangzhou Red Cross Hospital.

\section{Consent for publication}

Not applicable.

\section{Competing interests}

The authors declare that they have no competing interests.

\section{Author details}

'Department of Thoracic Surgery, Hangzhou Red Cross Hospital, Hangzhou 310003, China. ${ }^{2}$ Department of Nursing, Hangzhou Red Cross Hospital, Hangzhou 310003, China.
Received: 9 May 2020 Accepted: 15 June 2020

Published online: 19 June 2020

\section{References}

1. Tiberi S, du Plessis N, Walzl G, et al. Tuberculosis: progress and advances in development of new drugs, treatment regimens, and host-directed therapies [J]. Lancet Infect Dis. 2018;18(7):e183-98.

2. Zhu P, Mai M, Wu R, et al. Pericardiectomy for constrictive pericarditis: single-center experience in China [J]. J Cardiothorac Surg. 2015;10:34.

3. Mutyaba AK, Balkaran S, Cloete $\mathrm{R}$, et al. Constrictive pericarditis requiring pericardiectomy at Groote Schuur Hospital, Cape Town, South Africa: causes and perioperative outcomes in the HIV era (1990-2012)[J]. J Thorac Cardiovasc Surg. 2014;148(6):3058-3065.e3051.

4. Syed FF, Mayosi BM. A modern approach to tuberculous pericarditis [J]. Prog Cardiovasc Dis. 2007;50(3):218-36

5. Maisch B, Seferovic PM, Ristic AD, et al. Guidelines on the diagnosis and management of pericardial diseases executive summary; the task force on the diagnosis and management of pericardial diseases of the European society of cardiology [J]. Eur Heart J. 2004;25(7):587-610.

6. Tokuda Y, Miyata H, Motomura N, et al. Outcome of pericardiectomy for constrictive pericarditis in Japan: a nationwide outcome study [J]. Ann Thorac Surg. 2013;96(2):571-6.

7. Szabo G, Schmack B, Bulut C, et al. Constrictive pericarditis: risks, aetiologies and outcomes after total pericardiectomy: 24 years of experience [J]. Eur J Cardiothorac Surg. 2013;44(6):1023-8 discussion 1028.

8. Gopaldas RR, Dao TK, Caron NR, et al. Predictors of in-hospital complications after pericardiectomy: a nationwide outcomes study [J]. J Thorac Cardiovasc Surg. 2013;145(5):1227-33.

9. Chowdhury UK, Subramaniam GK, Kumar AS, et al. Pericardiectomy for constrictive pericarditis: a clinical, echocardiographic, and hemodynamic evaluation of two surgical techniques [J]. Ann Thorac Surg. 2006;81(2):5229.

10. Choi MS, Jeong DS, Oh JK, et al. Long-term results of radical pericardiectomy for constrictive pericarditis in Korean population [J]. J Cardiothorac Surg. 2019;14(1):32.

11. Cho YH, Schaff HV. Extent of pericardial resection for constrictive pericardiectomy [J]. Ann Thorac Surg. 2012;94(6):2180.

12. Welch TD. Constrictive pericarditis: diagnosis, management and clinical outcomes [J]. Heart. 2018;104(9):725-31.

13. Vistarini N, Chen C, Mazine A, et al. Pericardiectomy for constrictive pericarditis: 20 years of experience at the Montreal heart institute [J]. Ann Thorac Surg. 2015;100(1):107-13.

14. Pichel IA, Concepcion Fernandez Cimadevilla O, de la Hera JM, et al. Constrictive pericarditis: early diagnosis for a better prognosis [J]. J Thorac Cardiovasc Surg. 2014;148(4):1766.

15. Inamdar KY, Aikebaier M. Lijunhong, et al. Pericardiectomy: prompt surgical management of constrictive pericarditis [J]. Heart Surg Forum. 2014;17(6): E319-22.

16. Talreja DR, Nishimura RA, Oh JK, et al. Constrictive pericarditis in the modern era: novel criteria for diagnosis in the cardiac catheterization laboratory [J]. J Am Coll Cardiol. 2008;51(3):315-9.

17. Adler Y, Charron P, Imazio M, et al. 2015 ESC Guidelines for the diagnosis and management of pericardial diseases: The Task Force for the Diagnosis and Management of Pericardial Diseases of the European Society of Cardiology (ESC) endorsed by: the European Association for Cardio-Thoracic Surgery (EACTS)[J]. Eur Heart J. 2015;36(42):2921-64.

18. Nozohoor S, Johansson M, Koul B, et al. Radical pericardiectomy for chronic constrictive pericarditis [J]. J Card Surg. 2018;33(6):301-7.

19. Depboylu BC, Mootoosamy P, Vistarini N, et al. Surgical treatment of constrictive pericarditis [J]. Tex Heart Inst J. 2017;44(2):101-6.

20. Busch C, Penov K, Amorim PA, et al. Risk factors for mortality after pericardiectomy for chronic constrictive pericarditis in a large single-centre cohort [J]. Eur J Cardiothorac Surg. 2015;48(6):e110-6.

21. George TJ, Arnaoutakis GJ, Beaty CA, et al. Contemporary etiologies, risk factors, and outcomes after pericardiectomy [J]. Ann Thorac Surg. 2012; 94(2):445-51.

22. Ghavidel AA, Gholampour M, Kyavar M, et al. Constrictive pericarditis treated by surgery [J]. Tex Heart Inst J. 2012;39(2):199-205.

23. Nishimura S, Izumi C, Amano M, et al. Long-term clinical outcomes and prognostic factors after pericardiectomy for constrictive pericarditis in a Japanese population [J]. Circ J. 2017;81(2):206-12. 
24. Rupprecht L, Putz C, Florchinger B, et al. Pericardiectomy for constrictive pericarditis: an Institution's 21 years experience [J]. Thorac Cardiovasc Surg. 2018;66(8):645-50.

25. Acharya A, Koirala R, Rajbhandari N, et al. Anterior pericardiectomy for postinfective constrictive pericarditis: intermediate-term outcomes [J]. Ann Thorac Surg. 2018;106(4):1178-81.

\section{Publisher's Note}

Springer Nature remains neutral with regard to jurisdictional claims in published maps and institutional affiliations.

- fast, convenient online submission

- thorough peer review by experienced researchers in your field

- rapid publication on acceptance

- support for research data, including large and complex data types

- gold Open Access which fosters wider collaboration and increased citations

- maximum visibility for your research: over $100 \mathrm{M}$ website views per year

At $\mathrm{BMC}$, research is always in progress. 